\title{
Interleukin 17 and Pro-hepcidin in Anemia and Erythropoietin Responsiveness of Chronic Kidney Disease Patients Treated with Hemodialysis
}

Anca Rusu ${ }^{1 *}$, Ina Kacso ${ }^{2}$, Simona Racasan ${ }^{3}$ and Mirela Gherman Caprioara ${ }^{2}$

${ }^{1}$ Rena Clinic Dyalisis Center Cluj Napoca, Romania

${ }^{2}$ University of Medicine and Pharmacy, Nephrology Clinic Mihai Manasia, Cluj Napoca, Romania

${ }^{3}$ Nefromed Dialysis Center, Cluj Napoca, Romania

\begin{abstract}
Background: Monocytes and granulocytes, activated by contact with hemodialysis membranes, generate increased cytokine secretion, an important key in pathogenesis of anemia and erythropoietin (rHuEPO) resistance. We aimed to examine the correlation of IL-17 and pro-hepcidin with anemia of chronic kidney disease (CKD) patients treated with hemodialysis (HD).

Method: 69 HD patients were included. Exclusion criteria were: neoplasia, acute infections, blood loss, absolute iron deficiency. IL-17 and pro-hepcidin were determined. Hemoglobin, ferritin, transferrin and transferrin saturation were measured. rHuEPO responsiveness index was calculated. A poor response to rHuEPO was defined as rHuEPO responsiveness index $>200$.

Results: Mean level of IL-17 was $33.3 \pm 5.1 \mathrm{pg} / \mathrm{ml}$ and pro-hepcidin was $336.6 \pm 23.7 \mathrm{pg} / \mathrm{ml}$. IL-17 and pro-hepcidin negatively correlated with hemoglobin $(R 0.503, p<0.001$ and $R 0.693, p<0.001)$ and with transferrin saturation $(R 0.306$, $p=0.01 ; R 0.455, p=0.002)$ and positively correlated with rHuEPO responsiveness index $(R 0.416, p<0.001 ; R 0.674$, $\mathrm{p}<0.001)$. Patients with rHuEPO index>200 had higher pro-hepcidin $(432.5 \pm 25$ vs. $157.5 \pm 12 \mathrm{pg} / \mathrm{ml}, \mathrm{p}<0.001)$, increased IL-17 $(27 \pm 1.9$ vs. $4.9 \pm 0.3 \mathrm{pg} / \mathrm{ml}, \mathrm{p}<0.001)$, and lower iron biodisponibility (transferrin saturation $18 \pm$ $1.6 \%$ vs. $31 \pm 1.2 \%$; $p<0.001$ ) than those with rHuEPO responsiveness index<200. IL-17 positively correlated with prohepcidin (R0.454, $\mathrm{p}<0.001)$.
\end{abstract}

Conclusion: High levels of IL-17 and pro-hepcidin are both correlated with low hemoglobin, poor response to rHuEPO and decreased iron biodisponibility in hemodialysis patients.

Keywords: Hepcidin; Anemia; Interleukin 17; Inflammation; Erythropoietin hyporesponsiveness; Iron availability

\section{Introduction}

Anemia is an important cause of morbidity and mortality in all end stage renal disease patients and particularly in those treated with chronic hemodialysis. Erythropoiesis stimulating agents (ESA) improved anemia treatment in these patients but it has been observed that up to $12-15 \%$ of hemodialysis patients have a poor response to erythropoietin administration [1-3]. Decreased iron availability for erythropoiesis is one of the important causes of anemia in these patients. The role of inflammation as a factor of reduce iron biodisponibility and erythropoietin hyporesponsiveness has been intensively studied lately. Despite worldwide efforts there are many missing links in the pathogenesis of anemia and erythropoietin resistance in chronic hemodialysis patients. Monocytes and granulocytes activated by contact with extracorporeal hemodialysis membranes generate increased cytokine secretion. The role of IL2, IL6, TNF alfa, IFN gamma in anemia of inflammatory and chronic kidney diseases has been previously demonstrated [2-5]. Hepcidin is an acute phase protein which seems to be involved in iron metabolism and it's liver synthesis is induced by some proinflammatory cytokines such as IL6, IFN gamma [6-15]. Hepcidin-25 is the biologically active form of the hormone resulted from the cleavage of pro-hepcidin [16-18]. Experimental studies on mice and rats with chronic inflammatory diseases have shown that hepcidin increases macrophages iron intake and decreases macrophages iron outtake by inhibiting feroportin membrane channels [6,19-21]. A functional iron deficiency occurs as a result. Other factors involved in hepcidin regulation are anemia, hypoxia and iron deficiency. Iron administration increase hepatocyte transcription of gene for hepcidin synthesis $[10,12,22]$ while transferrin-bound iron decreases hepcidin levels [15]. Kidney plays an important role in hepcidin metabolism and patients with CKD have increased serum levels of pro-hepcidin, hepcidin, and hepcidin metabolites. The role of hepcidin in anemia and iron availability of hemodialysis patients is now under debate. Moreover, if both pro-hepcidin and hepcidin 25 are involved in the pathogenetic mechanisms is not well known as yet. Only few studies on hepcidin in anemia of chronic hemodialysis patients are available by now.

Even less studied was IL-17. It has been observed on experimental models that IL-17 inhibits medullar erythropoiesis [23-25] but as our knowledge there are no data about the role of IL-17 in anemia of chronic kidney disease and erythropoietin resistance.

The aim of our study was to examine the role of pro-hepcidin and IL-17 in anemia and erythropoietin responsiveness in patients with CKD treated with hemodialysis.

*Corresponding author: Anca Rusu, University of Medicine and Pharmacy, Nephrology Clinic Mihai Manasia, Rena Clinic Dialysis Center, Str Take Ionescu Nr 72, Cluj Napoca, 400476, Romania, Tel: 0040745359321; E-mail: flaviarusu@yahoo.com

Received April 29, 2015; Accepted June 25, 2015; Published June 27, 2015

Citation: Rusu A, Kacso I, Racasan S, Caprioara GM (2015) Interleukin 17 and Pro-hepcidin in Anemia and Erythropoietin Responsiveness of Chronic Kidney Disease Patients Treated with Hemodialysis. Med chem 5: 290-294. doi: 10.4172/2161-0444.1000277

Copyright: $\odot 2015$ Rusu A, et al. This is an open-access article distributed under the terms of the Creative Commons Attribution License, which permits unrestricted use, distribution, and reproduction in any medium, provided the original author and source are credited. 


\section{Material and Methods}

Data of 145 patients with chronic kidney disease treated with chronic hemodialysis in Nefromed Dialysis Center Cluj Napoca, Romania, have been analyzed. Patients with neoplasia, blood loss, acute infections, absolute iron deficiency, severe secondary hyperparathyroidism, insufficient dialysis dose, cirrhosis, congestive heart failure have been excluded. Remaining 69 patients were included.

Patients' informed consent and the agreement from Ethics Committee of University of Medicine Cluj Napoca was obtained.

All patients received subcutaneous beta recombinant-human rHuEPO and folic acid orally. 16 healthy volunteers were included in a control group. Hemoglobin, hematocrit, serum iron, ferritin and transferrin were measured. Transferrin saturation was calculated as TSAT $=70.9 \times$ serum iron $(\mathrm{mcg} / \mathrm{dl}) /$ tranferrin $(\mathrm{mg} / \mathrm{dl})$. Serum ferritin $>100 \mathrm{ng} / \mathrm{ml}$ with $\mathrm{TSAT}<20 \%$ was considered functional iron deficiency. Administered $\mathrm{rHuEPO}$ doses (U/kg/week) were recorded. rHuEPO responsiveness index was calculated as rHuEPO $\mathrm{U} /$ week/hematocrit. $\mathrm{rHuEPO}$ index $>200$ was considered as $\mathrm{rHuEPO}$ hyporesponsiveness.

Serum pro-hepcidin was measured in hemodialysis patients and in controls using DRG Hepcidin Prohormon ELISA kit. $10 \mathrm{ml}$ peripheral venous blood samples was collected and serum separation was performed by centrifugation at $2500 \times \mathrm{g}$ for 10 minutes at $4^{\circ} \mathrm{C}$ and stored at $-20^{\circ} \mathrm{C}$ prior to pro-hepcidin measurement. IL-17 was determined in both hemodialysis patients and controls using ELISA kit. Peripheral blood sample was collected; serum was separated by centrifugation at $1000 \times \mathrm{g}$ for 15 minutes and stored at $-20^{\circ} \mathrm{C}$ before measurement of IL-17.

Statistical analysis was performed with SigmaStat using linear regression and t-test. Data is expressed as mean \pm SEM. Correlation of C Reactive Protein (CRP), IL-17 and pro-hepcidin with hemoglobin, serum ferritin, transferrin saturation, rHuEPO dose and rHuEPO responsiveness index was followed, as well as the correlation between CRP, IL-17 and pro-hepcidin.

\section{Results}

General characteristics of hemodialysis patients were as follows: mean age was $59 \pm 11$ years, males/females ratio $1.3 / 1$, mean time on dialysis was $4.8 \pm 1.1$ years. All patients received adequate dose of dialysis, expressed as mean KT/V $1.35 \pm 0.1$ (KT/V $>1.3$ is considered as normal). Mean CRP in hemodialysis patients was $7.2 \pm 3.4 \mathrm{mg} / \mathrm{l}$ vs. $1.1 \pm 0.5 \mathrm{mg} / \mathrm{l}$ in controls $(\mathrm{p}<0.001)$. Serum level of IL-17 was $53.3 \pm$ $23.1 \mathrm{pg} / \mathrm{ml}$ in hmodialysis patients vs. $36.3 \pm 21.1 \mathrm{pg} / \mathrm{ml}$ in controls $(\mathrm{p}=0.002)$. High levels of pro-hepcidin were find in hemodialysis patients as compared to controls $(336.6 \pm 123.7 \mathrm{pg} / \mathrm{ml}$ vs. $83.2 \pm 57.3$ $\mathrm{pg} / \mathrm{ml}, \mathrm{p}<0.001)$.

Biological parameters, rHuEPO dose and $\mathrm{rHuEPO}$ responsiveness index in hemodialysis patients are listed in Table 1.

Correlation of IL-17 with hemoglobin and $\mathrm{rHuEPO}$ responsiveness index are presented in Figures 1 and 2. High dose of administered rHuEPO correlated with high levels of IL-17 ( $\mathrm{p}<0.001, \mathrm{R} 0.426)$.

We found a positive correlation of pro-hepcidin and IL-17 with CRP ( $\mathrm{p}<0.001, \mathrm{R}=0.437$ and $\mathrm{P}=0.02, \mathrm{R}=0.367$ respectively), as well as a positive correlation between IL-17 and pro-hepcidin $(\mathrm{p}<0.01$, $\mathrm{R}=0.454$ ). A positive correlation of pro-hepcidin and IL-17 with serum ferritin has also been observed $(\mathrm{p}<0.01, \mathrm{R} 0.594$ and $\mathrm{p}=0.03, \mathrm{R}=0.254$ respectively), as well as with transferrin saturation ( $\mathrm{p}=0.002, \mathrm{R}=0.455$ and $\mathrm{p}=0.01, \mathrm{R}=0.306$ ).

\begin{tabular}{|l|c|}
\hline & Mean \pm SD \\
\hline $\mathrm{Hb}(\mathrm{g} / \mathrm{dl})$ & $10.6 \pm 1.7$ \\
\hline $\mathrm{Ht}(\%)$ & $32.5 \pm 4.6$ \\
\hline Serum iron $(\mu \mathrm{g} / \mathrm{dl})$ & $61.1 \pm 3.2$ \\
\hline Serum ferritin $(\mathrm{ng} / \mathrm{ml})$ & $767.2 \pm 47.3$ \\
\hline Transferrin saturation $(\%)$ & $27.1 \pm 9.4$ \\
\hline rHuEPO dose $(\mathrm{U} / \mathrm{kg} /$ week $)$ & $104 \pm 15.2$ \\
\hline rHuEPO responsiveness index $(\mathrm{U} /$ week/Ht) & $249 \pm 15.9$ \\
\hline
\end{tabular}

Table 1: Biological parameters, rHuEPO dose and rHuEPO responsiveness index in studied hemodialysis patients.

Pro-hepcidin positively correlated with required rHuEPO dose in chronic hemodialysis patients $(\mathrm{p}<0.001, \mathrm{R}=0.453)$. Correlation of hepcidin with hemoglobin and rHuEPO responsiveness index is presented in Figures 3 and 4.

CRP, IL-17 and pro-hepcidin as well as hemoglobin, serum ferritin and transferrin saturation in $\mathrm{HHEPO}$ hyporesponsiveness patients as compared to good responders are presented in Table 2.

IL 17 and pro-hepcidin levels were higher in patients with decreased transferrin saturation as compared with those with normal transferrin saturation $(26.8 \pm 1.9$ vs $6.1 \pm 0.4 \mathrm{pg} / \mathrm{ml}, \mathrm{p}=0.001 ; 477.5 \pm 39$ vs $157.5 \pm$ $12.5 \mathrm{pg} / \mathrm{ml}, \mathrm{p}<0.001)$.

\section{Discussions}

The most important findings of present study are the correlations of pro-hepcidin and IL-17 with anemia, reduced iron availability and poor response to erythropoietin treatment in chronic hemodialysis patients, as well as the correlation between IL-17 and pro-hepcidin.

This study showed an increased inflammatory state in chronic hemodialysis patients, expressed as increased levels of CRP, high levels of IL-17 and of pro-hepcidin. Chronic hemodialysis patients had higher levels of CRP, IL-17 and pro-hepcidin as compared to the controls.

There are only few previous studies showing increased levels of pro-hepcidin and hepcidin in chronic hemodialysis patients [16,2633] while as our knowledge there are missing data about IL-17 on this population.

Pro-hepcidin positively correlated with CRP in our patients despite other studies which reported no correlation between pro-hepcidin and CRP in chronic hemodialysis patients. Valenti et al. recently demonstrated a positive correlation between hepcidin- 25 and CRP in hemodyalisis population but they found no correlation of CRP with pro-hepcidin [34]. Moreover we found a negative correlation of IL-17 and pro-hepcidin with hemoglobin as shown in Figures 1 and 3. There are few authors doubting about the correlation of pro-hepcidin with the active form of hepcidin [35-38]. Weiss et al. found that pro-hepcidin does not correlate either with hepcidin or with inflammation markers, anemia and iron deficiency in chronic hemodialysis patients [16] while in our study we found a correlation of pro-hepcidin with CRP, IL-17 as well as with anemia, functional iron deficiency and rHuEPO hyporesponsiveness.

Inflammation has shown to be a major regulator for hepcidin synthesis resulting in increased levels of hepcidin [12]. IL-6 has been proved to be a trigger for hepcidin synthesis but the role of IL-17 in hepcidin regulation and in iron metabolism has not been reported in the literature. Only a few experimental studies reported a possible role of IL-17 in inhibition of medullar hematopoietic progenitors cell proliferation [24,25]. To demonstrate if IL-17 is involved in hepcidin regulation or not further studies are required. 


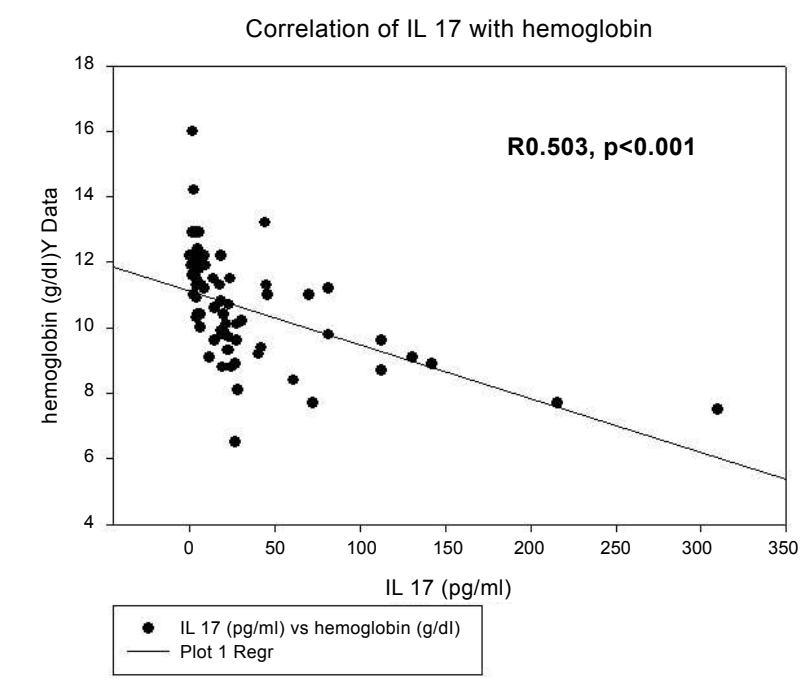

Figure 1: Correlation between IL17 and hemoglobin in chronic hemodialysis patients.

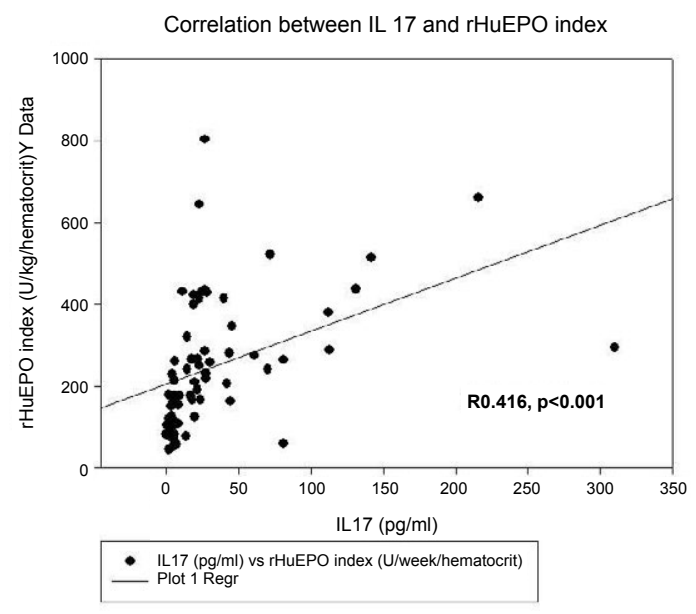

Figure 2: Correlation of IL17 with rHuEPO responsiveness index in chronic hemodialysis patients.

IL-17 and pro-hepcidin positively correlated with administered rHuEPO dose and with rHuEPO responsiveness index (Figures 2 and 4). Patients with high levels of pro-hepcidin received higher doses of $\mathrm{rHuEPO}$ and had a poor response to $\mathrm{rHuEPO}$ as compared to the others. Both IL-17 and pro-hepcidin displayed a positive correlation with serum ferritin and negative correlation with transferrin saturation. We found higher levels of IL-17 and pro-hepcidin in patients with decreased transferrin saturation than in patients with higher transferrin saturation, meaning that functional iron deficiency is correlated with high levels of IL-17 and pro-hepcidin. Our results are important showing that pro-hepcidin is linked to reduced iron availability and high rHuEPO doses, while some in vitro and animals studies proved that erythropoietin can block hepcidin expression; Weiss et al. found that rHuEPO administration to the end of dialysis session decreases hepcidin levels [16,39,40]; anyway all these studies, including the present one, were performed on a small number of patients and larger investigations are needed to elucidate the mechanisms of hepcidin in anemia, iron availability and anemia treatment in chronic hemodialysis patients.

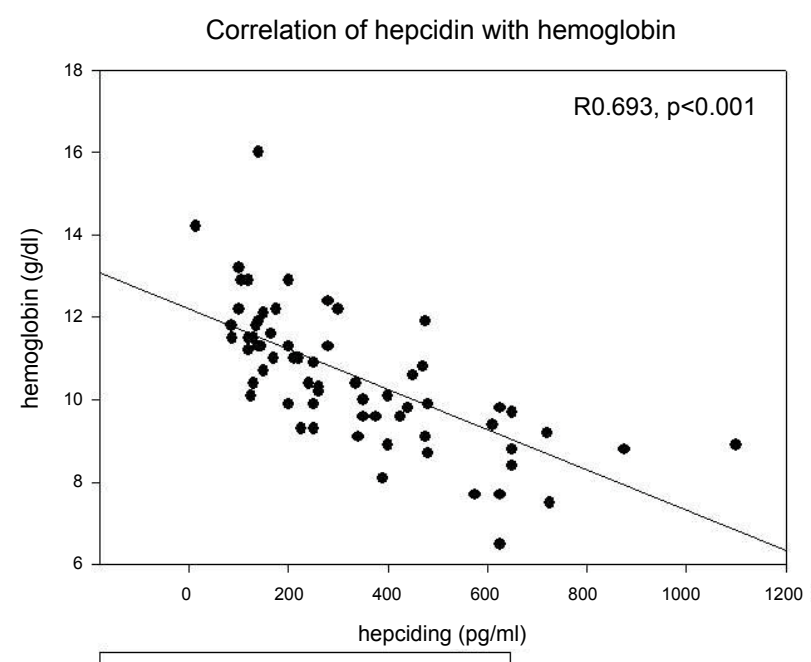

- hepciding (pg/ml) vs hemoglobin ( $/$ /dl) Plot 1 Regr

Figure 3: Correlation between pro-hepcidin and hemoglobin in chronic hemodialysis patients.

Correlation between hepcidin and rHuEPO responsiveness index

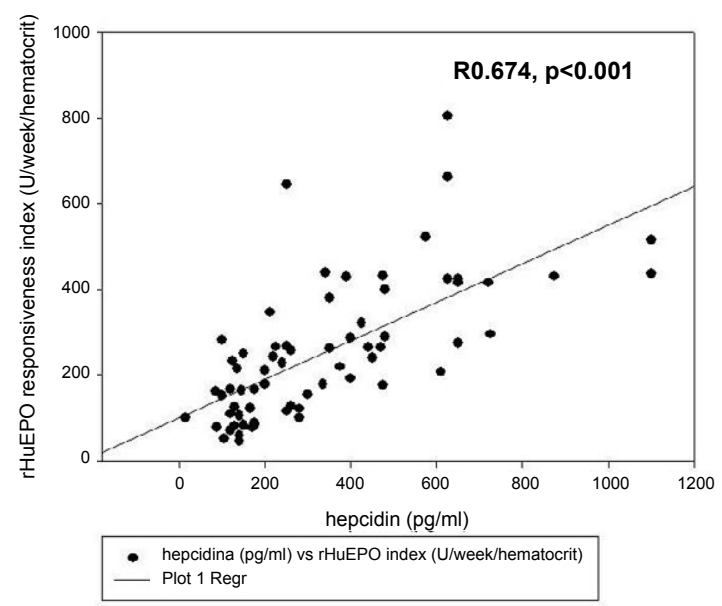

Figure 4: Correlation of pro-hepcidin with rHuEPO responsiveness index in chronic hemodialysis patients.

A positive correlation between IL-17 and pro-hepcidin has found in this study which as our knowledge has not been previously demonstrated. The role of IL-17 in iron metabolism and hepcidin regulation is to be further investigated.

Some authors found a decrease of hepcidin levels to the end of dialysis [16]; to demonstrate the role of hemodialysis and hemodialysis modality in hepcidin regulation further investigations are required; in our studies all patients received the same hemodialysis regimen regarding to the length of sessions, frequency and hemodialysis membranes.

Experimental and human studies demonstrated that anemia and iron deficiency are the other two important regulators of hepcidin, decreasing hepcidin synthesis. Our findings of high levels of pro-hepcidin in anemic hemodialysis patients with functional iron deficiency and increased inflammatory state demonstrate that 
Citation: Rusu A, Kacso I, Racasan S, Caprioara GM (2015) Interleukin 17 and Pro-hepcidin in Anemia and Erythropoietin Responsiveness of Chronic Kidney Disease Patients Treated with Hemodialysis. Med chem 5: 290-294. doi: 10.4172/2161-0444.1000277

\begin{tabular}{|c|c|c|c|}
\hline & $\begin{array}{c}\text { rHuEPO } \\
\text { index<200* }\end{array}$ & $\begin{array}{c}\text { rHuEPO } \\
\text { index } \mathbf{2 0 0}^{\text {** }}\end{array}$ & $\mathbf{p}$ \\
\hline CRP & $0.9 \pm 0.42$ & $3.02 \pm 1.13$ & $<0.01$ \\
\hline IL17 & $4.9 \pm 0.3$ & 271.9 & $<0.001$ \\
\hline Pro-hepcidin & $157.5 \pm 12$ & $432.5 \pm 25$ & $<0.001$ \\
\hline Hemoglobin & 11.90 .6 & $9.1 \pm 0.8$ & 0.002 \\
\hline Serum ferritin & $335 \pm 68.4$ & $789 \pm 49.8$ & $<0.001$ \\
\hline Transferrin saturation & $31 \pm 1.2$ & $18 \pm 1.6$ & $<0.001$ \\
\hline $\begin{array}{c}\text { Administered rHuEPO } \\
\text { dose }\end{array}$ & $64.5 \pm 121.7$ & $181.36 \pm 44.83$ & $<0.001$ \\
\hline
\end{tabular}

${ }^{*}$ Good responders to rHuEPO therapy. ${ }^{* *}$ rHuEPO hyporesponsiveness patients.

Table 2: Inflammation markers, hemoglobin and iron status in rHuEPO hyporesponsiveness patients as compared to good responders.

hepcidin in hemodialysis patients is the cause of erythropoietin hyporesponsiveness by reducing iron availability in these patients; our data is consistent with those reported by Valenti et al [34].

In conclusion, both pro-hepcidin and IL-17 are correlated with anemia and poor response to $\mathrm{rHuEPO}$ treatment linked to decreased iron availability for erythropoiesis in chronic hemodialysis patients. Moreover, IL-17 correlates with pro-hepcidin, which, as our knowledge, has not been previously demonstrated. Further studies are required to investigate the role of IL-17 in hepcidin regulation, as well as in iron metabolism, in order to better understand the mechanisms of rHuEPO resistance and to improve the management of anemic hemodialysis patients.

\section{Acknowledgments}

We thank you to Nefromed Dialysis Center Cluj Napoca, Romania and to Dr IMPatiu for helping us to recruit patients. This study was supported by a grant from the National Council of Scientific Research in Higher Education (CNCSIS Romania) and University of Medicine and Pharmacy Cluj Napoca Romania (TD number 584/2008-2009).

\section{References}

1. Toto RD (2003) Anemia of chronic disease: past, present, and future. Kidney Int Suppl: S20-23.

2. Ifudu O, Uribarri J, Rajwani I, Vlacich V, Reydel K, et al. (2002) Low hwmatocrit may connote malnutrition/inflammation syndrome in hemodialysis patients. Dial Transplant 31: 845-848.

3. Macdougall IC, Cooper AC (2002) Erythropoietin resistance: the role of inflammation and pro-inflammatory cytokines. Nephrol Dial Transplant Suppl 11: 39-43.

4. Amore A, Coppo R (2002) Immunological basis of inflammation in dialysis. Nephrol Dial Transplant Suppl 8: 16-24.

5. Pertosa G, Grandaliano G, Gesualdo L, Schena FP (2000) Clinical relevance of cytokine production in hemodialysis. Kidney Int Suppl 76: S104-111.

6. Weiss G, Goodnough LT (2005) Anemia of chronic disease. N Engl J Med 352: 1011-1023.

7. Deicher R, Horl WH (2004) Hepcidin: a molecular link between inflammation and anaemia. Nephrol Dial Transplant 19: 521-524.

8. Park CH, Valore EV, Waring AJ, Ganz T (2001) Hepcidin, a urinary antimicrobial peptide synthesized in the liver. J Biol Chem 276: 7806-7810.

9. Pigeon C, llyin G, Courselaud B, Leroyer P, Turlin B, et al. (2001) A new mouse liver-specific gene, encoding a protein homologous to human antimicrobial peptide hepcidin, is overexpressed during iron overload. J Biol Chem 276: 7811-7819.

10. Nemeth E, Rivera S, Gabayan V, Keller C, Taudorf S, et al. (2004) IL-6 mediates hypoferremia of inflammation by inducing the synthesis of the iron regulatory hormone hepcidin. J Clin Invest 113: 1271-1276.

11. Nicolas G, Chauvet C, Viatte L, Danan JL, Bigard X, et al. (2002) The gene encoding the iron regulatory peptide hepcidin is regulated by anemia, hypoxia, and inflammation. J Clin Invest 110: 1037-1044.

12. Coyne DW (2011) Hepcidin: clinical utility as a diagnostic tool and therapeutic target. Kidney Int 80: 240-244.

13. Ganz T, Nemeth E (2006) Iron imports. IV. Hepcidin and regulation of body iron metabolism. Am J Physiol Gastrointest Liver Physiol 290: G199-203.

14. Babitt JL, Lin HY (2010) Molecular mechanisms of hepcidin regulation implications for the anemia of CKD. Am J Kidney Dis 55: 726-741.

15. Lin L, Valore EV, Nemeth E, Goodnough JB, Gabayan V, et al. (2007) Iron transferrin regulates hepcidin synthesis in primary hepatocyte culture through hemojuvelin and BMP2/4. Blood 110: 2182-2189.

16. Weiss G, Theurl I, Eder S, Koppelstaetter C, Kurz K, et al. (2009) Serum hepcidin concentration in chronic haemodialysis patients: associations and effects of dialysis, iron and erythropoietin therapy. Eur J Clin Invest 39: 883890

17. Park CH, Valore EV, Waring AJ, Ganz T (2001) Hepcidin, a urinary antimicrobial peptide synthesized in the liver. J Biol Chem 276: 7806-7810.

18. Pigeon C, Ilyin G, Courselaud B, Leroyer P, Turlin B, et al. (2001) A new mouse liver-specific gene, encoding a protein homologous to human antimicrobial peptide hepcidin, is overexpressed during iron overload. J Biol Chem 276: 7811-7819.

19. Laftah AH, Ramesh B, Simpson RJ, Solanky N, Bahram S, et al. (2004) Effect of hepcidin on intestinal iron absorption in mice. Blood 103: 3940-3944.

20. Frazer DM, Wilkins SJ, Becker EM, Vulpe CD, McKie AT, et al. (2002) Hepcidin expression inversely correlates with the expression of duodenal iron transporters and iron absorption in rats. Gastroenterology 123: 835-844.

21. Yang F, Liu XB, Quinones M, Melby PC, Ghio A, et al. (2002) Regulation of reticuloendothelial iron transporter MTP1 (Slc11a3) by inflammation. J Biol Chem 290: 39786-39791.

22. Pigeon C, Ilyin G, Courselaud B, Leroyer P, Turlin B, et al. (2001) A new mouse liver-specific gene, encoding a protein homologous to human antimicrobial peptide hepcidin, is overexpressed during iron overload. J Biol Chem 276: 7811-7819.

23. Jovcic G, Bugarski D, Krstic A, Vlaski M, Petakov M, et al. (2007) The effect of interleukin-17 on hematopoietic cells and cytokine release in mouse spleen. Physiol Res 56: 331-339.

24. Bugarski D, Krstic A, Mojsilovic S, Vlaski M, Petakov M, et al. (2007) Signaling pathways implicated in hematopoietic progenitor cell proliferation and differentiation. Exp Biol Med (Maywood) 232: 156-163.

25. Jovcic G, Bugarski D, Petakov M, Krstic A, Vlaski M, et al. (2004) In vivo effects of interleukin-17 on haematopoietic cells and cytokine release in normal mice. Cell Prolif 37: 401-412.

26. Malyszko J, Malyszko JS, Hryszko T, Pawlak K, Mysliwiec M (2005) Is hepcidin a link between anemia, inflammation and liver function in hemodialyzed patients? Am J Nephrol 25: 586-590.

27. Eleftheriadis T, Kartsios C, Liakopoulos V, Antoniadi G, Ditsa M, et al. (2006) Does hepcidin affect erythropoiesis in hemodialysis patients? Acta Haematol 116: 238-244.

28. Tomosugi N, Kawabata H, Wakatabe R, Higuchi M, Yamaya $\mathrm{H}$, et al. (2006) Detection of serum hepcidin in renal failure and inflammation by using ProteinChip System. Blood 108: 1381-1387.

29. Ashby DR, Gale DP, Busbridge M, Murphy KG, Duncan ND, et al. (2009) Plasma hepcidin levels are elevated but responsive to erythropoietin therapy in renal disease. Kidney Int 75: 976-981.

30. Zaritsky J, Young B, Wang HJ, Westerman M, Olbina G, et al. (2009) Hepcidin-a potential novel biomarker for iron status in chronic kidney disease. Clin J Am Soc Nephrol 4: 1051-1056.

31. Peters HP, Laarakkers CM, Swinkels DW, Wetzels JF (2010) Serum hepcidin-25 levels in patients with chronic kidney disease are independent of glomerular filtration rate. Nephrol Dial Transplant 25: 848-853.

32. Weiss G, Theurl I, Eder S, Koppelstaetter C, Kurz K, et al. (2009) Serum hepcidin concentration in chronic haemodialysis patients: associations and effects of dialysis, iron and erythropoietin therapy. Eur J Clin Invest 39: 883890.

33. Ford BA, Eby CS, Scott MG, Coyne DW (2010) Intra-individual variability in serum hepcidin precludes its use as a marker of iron status in hemodialysis patients. Kidney Int 78: 769-773.

34. Valenti L, Girelli D, Valenti GF, Castagna A, Como G, et al. (2009) HFE mutations 
Citation: Rusu A, Kacso I, Racasan S, Caprioara GM (2015) Interleukin 17 and Pro-hepcidin in Anemia and Erythropoietin Responsiveness of Chronic Kidney Disease Patients Treated with Hemodialysis. Med chem 5: 290-294. doi: 10.4172/2161-0444.1000277

modulate the effect of iron on serum hepcidin-25 in chronic hemodialysis patients. Clin J Am Soc Nephrol 4: 1331-1337.

35. Kemna EH, Kartikasari AE, Tits LJ, Pickkers P, Tjalsma H, et al. (2008) Regulation of hepcidin: insights from biochemical analyses on human serum samples. Blood Cells Mol Dis 40: 339-346.

36. Roe MA, Spinks C, Heath AL, Harvey LJ, Foxall R, et al. (2007) Serum prohepcidin concentration: no association with iron absorption in healthy men; and no relationship with iron status in men carrying HFE mutations, hereditary haemochromatosis patients undergoing phlebotomy treatment, or pregnant women. Br J Nutr 97: 544-549.
37. Kato A, Tsuji T, Luo J, Sakao Y, Yasuda H, et al. (2008) Association of prohepcidin and hepcidin-25 with erythropoietin response and ferritin in hemodialysis patients. Am J Nephrol 28: 115-121.

38. Swinkels DW, Girelli D, Laarakkers C, Kroot J, Campostrini N, et al. (2008) Advances in quantitative hepcidin measurements by time-of-flight mass spectrometry. PLoS One 3: e2706.

39. Nicolas G, Viatte L, Bennoun M, Beaumont C, Kahn A, et al. (2002) Hepcidin, a new iron regulatory peptide. Blood Cells Mol Dis 29: 327-335.

40. Pinto JP, Ribeiro S, Pontes H, Thowfeequ S, Tosh D, et al. (2008) Erythropoietin mediates hepcidin expression in hepatocytes through EPOR signaling and regulation of C/EBPalpha. Blood 111: 5727-5733. 